\title{
Effect of sowing method and fertiliser application on establishment and first season growth of Caucasian clover
}

\author{
A.J.E. MOORHEAD', J.G.H. WHITE', P. JARVIS', R.J. LUCAS' and J.R. SEDCOLE ${ }^{2}$ \\ 'Plant Science Department, ${ }^{2}$ Centre for Computing and Biometrics, PO Box 84, Lincoln University
}

\section{Abstract}

A trial to measure the effects of establishment techniques and fertiliser application on seedling establishment and early root and rhizome development of Caucasian clover (Trifolium ambiguum) was sown in early October 1992, on a low-fertility, depleted short tussock grassland site at Mesopotamia Station, South Canterbury. Three sowing techniques, broadcasting, sod seeding and strip seeding, each with, two rates of fertiliser, 150 or $300 \mathrm{~kg} / \mathrm{ha}$ molybdic sulphur superphosphate, were used. By mid December, 48 and $38 \%$ establishment had occurred in the strip and sod seeding respectively, but only $9 \%$ in the broadcast. Strip seeding was the most successful technique. resulting in earlier rhizome and taproot development and wider lateral spread of rhizomes. However, both strip seeding and sod seeding resulted in all plants developing rhizomes 9 months after sowing. Plants from broadcasting were small with few rhizomes in the first season. The higher fertiliser rate improved establishment and growth, particularly in the strip seeding

-treatment;-By-using-a-strip-seeding-technioue Caucasian clover was established as rapidly-as white clover and plants of both species were similar in size after 5 months.

K eywords: broadcast seeding, establishment, fertiliser, rhizomes, sod seeding, sowing methods, Trifolium ambiguum, Trifolium repens, tussock grasslands

\section{Introduction}

Caucasian clover shows great promise as a very persistent, competitive legume for the South Island hill and high country. It is a deep-rooted, droughttolerant, spring- and summer-growing legume which can tolerate low winter temperatures and heavy frosts, and recovers quickly after drought (Dear \& Zorin 1985; Woodman et al. 1992). Caucasian clover has an extensive root and rhizome system (Daly \& Mason 1987) which acts as an important store for nutrients (Strachan et al. 1994). Allan \& Keoghan (1994) found that Caucasian clover persisted under a wide range of grazing management systems because the rhizomes and growing points were below ground level. Vegetative spread was observed by Dear \& Zorin (1985) who found 4-year-old Caucasian clover cv. Monaro produced 74 daughter plants/plant and, had rhizomes nearly $500 \mathrm{~mm}$ in length.

Reports of slow establishment (Lucas et al. 1980; Scott 1985) and the lack of seed supplies have restricted the commercial use of Caucasian clover. This has led to proposals that rhizome fragments could be used as a means of establishment (Scott \& Mason 1992). However, in contrast to Lucas et al. (1980), Lowther \& Patrick (1992) reported seedling establishment of white clover and Caucasian clover to be similar.

The aims of this establishment trial were to measure the effects of sowing technique and fertiliser application on Caucasian clover seedling establishment and early root and rhizome development on a lowfertility, summer-moist, high-country site.

\section{$M$ aterial and methods}

\section{Experimental site and design}

The experiment was sited on depleted, unimproved tussock grassland dominated $\mathrm{b} \bar{y}$ fescue tussock (Festuca novae zelandiae), brdwntop. (Agrostis capillaris) and. Hieracium pilosella situated at Mesopotamia Station in the upper Rangitata valley. The soil, a Mesopotamia silt loam, is acid (pH 5.2) and low in phosphorus (Olsen $\mathbf{P}$ 6) and sulphur (S 2 $\mathrm{ppm})$. The site is $500 \mathrm{~m}$ above sea level and has a mean annual rainfall of $940 \mathrm{~mm}$. The experimental site was burnt to remove litter and sown with Caucasian clover (Trifolium ambiguum Bieb.) cv. Monaro on 1 October 1992 using the Lincoln Ventures/AgResearch experimental plot drill. Rainfall was reasonably evenly distributed during the establishment year with 133 $\mathrm{mm}$ of rain in the two months following sowing out of a total for spring of $167 \mathrm{~mm}$ (Table 1).

Seeds were scarified and commercially prepared as a special batch by inoculating with Rhizobium strain $\mathrm{CC} 283 \mathrm{~B}$ followed by coating with tine lime at a rate of 0.7 lime : 1.0 seed. Although no Rhizobium counts were done the inoculant was applied at 5 times the recommended rate, with the aim that the number of viable Rhizobium present on the seed would not be limiting. The inoculated, coated seed was stored at 
Table 1 Seasonal rainfall and soil temperatures at Mesopotamia station, Rangitata valley, for the period 1992-1994.

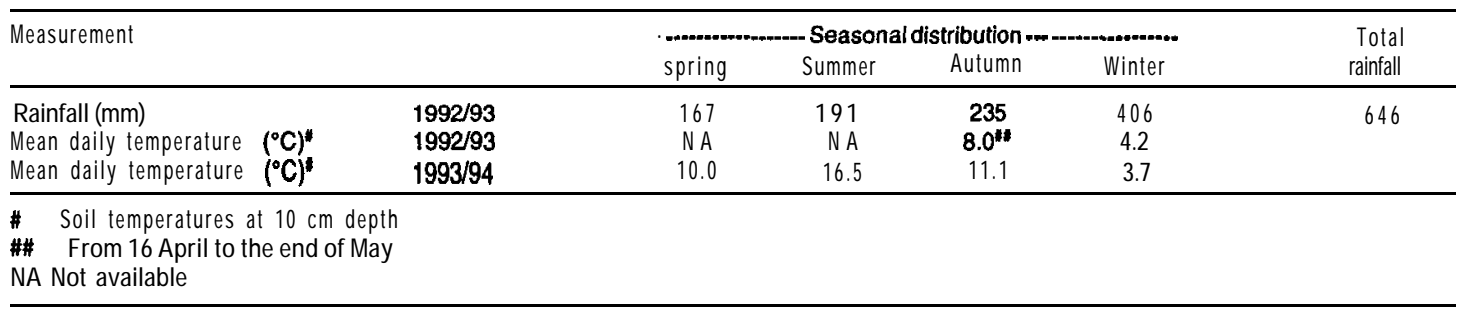

$4^{\circ} \mathrm{C}$ for 1 day before sowing. The trial was a balanced incomplete block design with plots consisting of paired comparisons of all treatments. The trial was replicated twice with each paired plot $20 \mathrm{~m}$ in length. Seeding rate was calculated to place 100 viable seeds per metre of row. Treatments consisted of 3 methocls of establishment: an experimental strip seeding system, direct seeding into the sod or broadcast. The strip seeding system, described fully by Horrell et al. (199 I), used an inclined dished disc to cut and invert a ribbon of turf, placing it adjacent to the drilling strip. Next, a spring tine cultivated the soil and banded the fertiliser at a nominal depth of $50 \mathrm{~mm}$. Finally a seed coulter sowed the seed at a shallow depth (approximately 10 $\mathrm{mm}$ ) and a press wheel firmed the seed bed. Two rows $150 \mathrm{~mm}$ apart were sown in the weed free $200 \mathrm{~mm}$ strip of bare soil. The sod seeding system used a Duncan 760 till seeder with a 'Baker' inverted T coulter form of direct drilling, with fertiliser placed with the seed. It was also drilled in two rows $150 \mathrm{~mm}$ apart. The broadcast treatment was sown by the plot drill with seed and fertiliser falling directly from the coulters and spreading over a $200 \mathrm{~mm}$ wide strip.

Each of the establishment methods was sown with either 150 or $300 \mathrm{~kg} / \mathrm{ha}$ of molybdic sulphur super phosphate $(8 \% \mathrm{P}, 20 \% \mathrm{~S})$. Basal boron was applied as a solution of borax $(11 \% \mathrm{~B})$ at $10 \mathrm{~kg} \mathrm{~B} / \mathrm{ha}$.

\section{Trial measurements and data analysis}

Early emergence and establishment was measured on 14 December 1992 with plant counts made along two $500 \mathrm{~mm}$ lengths of row from each paired treatment in each plot.

On 12 March 1993, one spade spit 200 x $150 \mathrm{~mm}$ was dug across each of the paired rows of sod and strip seeding treatments at median sites. Due to lack of uniform plant numbers in the broadcast treatment, spits were dug to obtain a minimum of 5 plants/ treatment. Samples were washed and measurements recorded on nodulation, rhizome number/plant and rhizome length. Dry weights of shoots (above-ground herbage), roots and rhizomes were determined.

At the end of the first growing season on 6 July
1993, one $150 \mathrm{~mm}$ wide turf was dug across the paired rows of the sod seed and strip seeding treatments. The turfs were long enough to include all lateral rhizome development. Five plants were randomly selected for measurement from the broadcast treatments. Measurements were the same 'as the first sampling plus additional measurements of secondary rhizome number and length.

An adjacent fertiliser trial comparing responses of Monaro Caucasian clover and Grasslands Tahora white clover to rates of phosphate and sulphur was also sampled. Both species were established on 1 October 1992 using the strip seiding technique. The treatment sampled for this study had $50 \mathrm{~kg} / \mathrm{ha}$ of both phosphorus and sulphur applied at sowing time. Three spits were dug from this Caucasian clover and white clover trial on 19 April 1993, and root, rhizome, stolon and leaf material measured.

The Genstat statistical package was used to analyse the paired plot design.

\section{Results and discussion}

\section{Germination and establishment}

The strip seeding system was the most successful method for establishment of Caucasian clover with $48 \%$ of seed sown establishing. This was closely followed by the sod seeding treatment $(\mathbf{3 8 \%})$, while broadcasting produced comparatively poor results (9\%) (Table 2). It is assumed that the success of strip seeding was due to a combination of effects including the physical removal of competing resident vegetation, cultivation to form a seed bed, formation of a microclimate and placement of fertiliser in a band below the seed. These all combined to enhance germination, nodulation and establishment of the seedlings and subsequent growth of roots and rhizomes (Tables 3 and 4). Similar results with the strip seeder have been achieved with other legume species by Lowther et al. (1991) and Woodman (1993). The sod seed technique was also satisfactory, indicating the importance of seed being placed in the ground close to fertiliser for establishment and subsequent growth in this 
environment. However, in drier environments the close proximity of fertiliser may be detrimental (Woodman pers. comm.). The poorer establishment from broadcasting can be attributed to a combination of factors but the main adverse influence may have been the substantial ground cover of $30-50 \%$ Hieracium pilosella leaves which would have resulted in a high proportion of seed landing on the prostrate rosettes rather than bare ground. In addition, both germinating seed and Rhizobium are very susceptible to desiccation when on the surface of the soil; this drying effect would have been further aided by lack of litter cover due to burning. About $80 \%$ of the plants in the broadcast plot were small and yellow at the March sampling. Some were un-nodulated while others had small pale nodules which could be the result of ineffective and/or late nodulation by Caucasian clover rhizobia. Alternatively this could be the result of nodulation by resident white clover rhizobia which may form small ineffective nodules on Caucasian clover (Patrick \& Lowther 1993; Ronson pers.comm.). It is possible that the most recent recommendation for inoculation (Patrick \& Lowther 1994) would have given better nodulation in the broadcast situation. However, the excellent nodulation of direct-drilled plants indicates that there were adequate numbers of rhizobia specific to Caucasian clover present for seed which is placed in soil rather than broadcast on the surface.

\section{Root and rhizome development}

A characteristic of Caucasian clover is its rapid early root development and by March 1993 some tap-roots $\sim$ from-the-strip-seeding-technique-had-reached-more than $700 \mathrm{~mm}$ depth. In contrast the broadcast plants had reached only $200 \mathrm{~mm}$ depth. At that time, root dry matter to $150 \mathrm{~mm}$ depth in the strip seeding system was more than double that of plants which were sod seeded, and almost 5 times the weight of broadcast plants (Table 3). There was an interaction between sowing method and fertiliser, with a larger response to the higher level of fertiliser in the strip seeding treatment. The root growth responses in March 1993 were presumably due to the same combination of factors which enhanced-germination and establishment mentioned earlier; the poorer growth of roots from sod seeding was assumed to be due to competition from browntop and Hieracium, particularly for nutrients such as phosphate (Jackman \& Mouat 1974; Svavarsdóttir pers. comm.).

By March 1993, rhizome development was evident on many plants of the sod seeded and strip seeding treatments although rhizome length and percentage of plants with rhizomes were greater with strip seeding
Table 2 Effect of establishment technique on percentage of Caucasian clover plants per metre of row in December 1992.

\begin{tabular}{|c|c|c|c|c|}
\hline \multicolumn{5}{|c|}{ Establishment techniaue } \\
\hline \multirow[t]{2}{*}{$\begin{array}{c}\text { Broadcast } \\
9\end{array}$} & & $\begin{array}{c}\text { Sod seeding } \\
39\end{array}$ & & $48^{\text {seeding }}$ \\
\hline & SED 4.44 & & & \\
\hline
\end{tabular}

Table 3 Effect of establishment technique on root weight ( $g / p$ lant) to $15 \mathrm{~cm}$ depth, March 1993.

\begin{tabular}{lcccccc}
\hline $\begin{array}{l}\text { Fertiliser } \\
(\mathrm{kg} / \mathrm{ha})\end{array}$ & Broadcast & Sod & seeding & Strip seeding & Mean & SED \\
\hline 150 & 0.143 & 0.276 & 0.526 & 0.316 & \\
300 & 0.157 & 0.376 & 0.657 & 0.464 & 0.055 \\
& & & & & & $(p<0.05)$ \\
\hline Mean & 0.150 & 0.326 & 0.693 & Interaction \\
SED & & 0.067 & $(p<0.001)$ & SED $0.095 \quad(p<0.05)$ \\
\hline
\end{tabular}

(Table 4). By July 1993 all plants in these two treatments had developed rhizomes. Few plants from broadcasting exhibited rhizomes either in March (Table 4) or in July. The rhizomes produced by the strip seeding system in March were 5 and 10 times the length of the sod seed and broadcast treatments respectively. Even at this early sampling, some rhizomes were $150 \mathrm{~mm}$ long in the strip seeding treatments. The reasons for this excellent rhizome development under the strip seeding system can be attributed to the plants establishing in a $200 \mathrm{~mm}$ wide cultivated seedbed free from strong Hieracium and browntop root competition. The sod seeded plants were subject to both inter and intra-specific competition as individual plants not only received substantial pressure from other Caucasian clover plants along the drill line, but any sideways growth resulted in strong competition from resident vegetation which formed a very dense root mat.

Table 4 Effect of establishment technique on percentage plants with rhizomes, average rhizome length, and root/rhizome:shoot ratios, in March 1993.

\begin{tabular}{|c|c|c|c|c|}
\hline & \multicolumn{2}{|c|}{.... $\quad$ Establishment } & technique ..... & \multirow[b]{2}{*}{ SED } \\
\hline & Broadcast & $\begin{array}{l}\text { Sod } \\
\text { seeding }\end{array}$ & $\begin{array}{l}\text { Strip } \\
\text { seeding }\end{array}$ & \\
\hline $\begin{array}{l}\text { Plants with } \\
\text { rhizomes (\%) }\end{array}$ & $!$ & 43 & 75 & $6.50(p<0.001)$ \\
\hline $\begin{array}{l}\text { Average rhizome } \\
\text { length }(\mathrm{mm})\end{array}$ & 2 & 4 & 21 & $2.26(p<0.001)$ \\
\hline $\begin{array}{l}\text { Root/rhizome: } \\
\text { shoot ratio }\end{array}$ & 2.49 & 3.15 & 3.36 & $0.21 \quad(p<0.001)$ \\
\hline
\end{tabular}


There was continued primary rhizome development in the autumn between the March 1993 sampling and the July 1993 sampling. By July 1993 the strip and sod seeded plants had developed secondary branch rhizomes (Table 5). Individual rhizomes from both the strip and sod seeding systems measured up to 300 $\mathrm{mm}$ in length, while the maximum plant width was 485 and $405 \mathrm{~mm}$ respectively (Table 5).

Table 5 Effect of establishment technique on the average primary and secondary rhizome length and maximum plant width in July 1993.

\begin{tabular}{|c|c|c|c|c|}
\hline & \multicolumn{2}{|c|}{ Establishment } & technique & \multirow[b]{2}{*}{ SED } \\
\hline & Broadcast & $\begin{array}{l}\text { Sod } \\
\text { seeding }\end{array}$ & $\begin{array}{c}\text { Strip } \\
\text { g seeding }\end{array}$ & \\
\hline $\begin{array}{l}\text { Primary rhizome } \\
\text { length }(\mathrm{mm})\end{array}$ & $8^{\prime \prime}$ & 30 & 78 & 5.5 \\
\hline $\begin{array}{l}\text { Secondary rhizome } \\
\text { length }(\mathrm{mm})\end{array}$ & 0 & $5^{*}$ & $32^{\prime}$ & 6.5 \\
\hline $\begin{array}{l}\text { Maximum plant } \\
\text { width }(m m)^{*}\end{array}$ & 35 & 405 & 485 & NA \\
\hline
\end{tabular}

\# Average of plants with rhizomes and secondary rhizomes. \# Plants measured from tip to tip of the two longest rhizomes.

Sampling done in mid spring of 1993 revealed further rhizome growth and development indicating that rhizome extension was not confined to autumn (Moorhead unpublished).

\section{Root plus rhizome to shoot ratio}

In contrast to many other clovers Caucasian clover seedlings allocate a much higher proportion of photosynthates into root and rhizome development than growth of leaves (Spencer et al. 1975). The rqot plus rhizome:shoot ratios present in the March sampling (Table 4) were very similar to those found by Daly \& Mason (1987) of 2.73 in cv. Prairie, and by Spencer et al. (1975) "who measured ratios of 2.36 and 3.36 in the diploid cv. Summit and a hexaploid ecotype respectively. These ratios emphasise the characteristic partitioning of nutrient and carbohydrate resources of Caucasian clover during its establishment into its root and rhizome systems. In March 1993 Caucasian clover had produced $10.7 \mathrm{~g} \mathbf{D M} / \mathrm{m}$ row of top growth using the strip seeding system and $3.7 \mathrm{~g} \mathrm{DM} / \mathrm{m}$ row for the sod seed technique. The herbage production by the strip seeding system (approx. $700 \mathrm{~kg} \mathrm{DM} / \mathrm{ha}$ at the row spacing used) together with the substantial underground biomass suggests that this treatment could have been lightly grazed within six months of establishment (Moorhead unpublished).

\section{Comparison with white clover}

Measurements of Caucasian clover and white clover plants drilled with the strip seeder in the adjacent fertiliser experiment showed large differences in their morphology. Individual 6-month-old white clover plants were similar in total leaf DM to Caucasian clover; but white clover plants had only one third the root DM while its stolons were nearly 3 times the weight of Caucasian clover rhizomes (Table 6). Caucasian clover, had longer tap-roots $>150 \mathrm{~mm}$ compared with $92 \mathrm{~mm}$ for white clover. Leaf DM yield was $8.4 \mathrm{~g} / \mathrm{m}$ row length vs $10 \mathrm{~g} / \mathrm{m}$ row length for white clover and Caucasian clover respectively.

\section{Conclusions}

Results showed the importance of good techniques for rapid establishment of Caucasian clover in moist, low fertility, depleted tussock grassland areas.

The most important conclusions are:

1. The use of either strip or sod seeding will produce large, rhizomatous, well established plants in the first season after sowing.

2. The strip and sod seeding establishment techniques are far superior to broadcasting and will produce a higher proportion of nodulated plants from seed sown.

3. Strip seeding will encourage earlier rhizome development and greater root production, causing faster vegetative spread, but sod seeding (which is the most commonly available technology) is also much superior to broadcasting.

4. By using the strip seeding technique Caucasian clover can be established as quickly and successfully as white clover in this environment.

5. High rates $(300 \mathrm{~kg} / \mathrm{ha})$ of molybdic sulphur superphosphate placed with or under the seed

Table 6 Comparison of white and Caucasian clover plants on 19 April 1993.

\begin{tabular}{|c|c|c|c|c|c|c|c|c|c|}
\hline \multirow[t]{2}{*}{ Species } & \multirow{2}{*}{$\begin{array}{c}\text { Average } \\
\text { plant } \\
\text { number } \\
\text { /m row }\end{array}$} & \multicolumn{3}{|c|}{ Individual plant DM } & \multirow{2}{*}{$\begin{array}{l}\text { Tap } \\
\text { root } \\
\text { length } \\
(\mathrm{mm})\end{array}$} & \multirow{2}{*}{$\begin{array}{c}\text { Tap } \\
\text { root } \\
\text { diameter } \\
(\mathrm{mm})\end{array}$} & \multicolumn{2}{|c|}{$\begin{array}{l}\text { Stolon/hizome } \\
\text { per plant }\end{array}$} & \multirow{2}{*}{$\begin{array}{c}\text { Leaf } \\
\text { numbe } \\
\text { per } \\
\text { plant }\end{array}$} \\
\hline & & Leaf & Aoot & $\begin{array}{l}\text { Stolon/ } \\
\text { rhizome }\end{array}$ & & & Number & Length $(\mathrm{mm})$ & \\
\hline White & 40 & 0.21 & 0.26 & 0.49 & 92 & 3.4 & 5 & 72 & 16.3 \\
\hline Caucasian & 50 & 0.20 & 0.81 & 0.16 & Z-150 & 4.6 & 4 & 44 & 5.2 \\
\hline
\end{tabular}


accelerates plant growth and rhizome development in this environment.

\section{ACKNOWLEDGEMENTS}

The research was funded by a grant from the Vernon Willey Trust. We thank Mr Laurie Prouting, Mesopotamia Station, Don Heffer for technical assistance, Russell Horrell for the use of the Lincoln Ventures/AgResearch experimental plot drill, Coated Seeds Ltd., Christchurch for coating seed and AGMARDT scholarship funding for A.J.E Moorhead.

\section{REFERENCES}

Allan, B.E.; Keoghan, J.M. 1994. More persistent legumes and grasses for oversown tussock country. Proceedings of the NZ Grassland Association 56: this volume.

Daly, G.T.; Mason, C.R. 1987. Performance of Caucasian and zigzag clovers. Proceedings of the NZ Grassland Association 48: 151 - 156.

Dear, B.S; Zorin, M. 1985. Persistence and productivity of Trifolium ambiguum M.Bieb. (Caucasian clover) in a high altitude region of south-eastern Australia. Australian journal of experimental agriculture 25: 124- 132.

Horrell, R.F.; Lowther, W.L.; Keoghan, J.M. 1991. Low cost overdrilling technology for pasture establishment. Proceedings of the NZ Grassland Association 53: 5 1-54.

Jackman, R.H.; Mouat, M.C.H. 1974. Browntop and pasture nutrition. Proceedings of the NZ Grassland Association 35: $95-100$

Lowther, W.L.; Fraser, W.J.; Horrell, R.F.; Johnstone, P.D. 1991. Comparison of pasture establishment from a conventional disc drill and a prototype strip seeder drill. Proceedings of the NZ Grassland Association 53: 47-50.

Lowther, W.L.; Patrick, H.N. 1992. Seedling establishment characteristics of alternative legume species in tussock grassland environments.
Proceedings of the NZ Grassland Association 54: 111-114.

Lucas, R.J.; White, J.G.H.; Daly, G.T.; Jarvis, P.; Meijer, G. 1980. Lotus, white clover and Caucasian clover oversowing, Mesopotamia Station, South Canterbury. Proceedings of the NZ Grassland Association 42: 142-151.

Patrick, H.N.; Lowther, W.L. 1993. Influence of the number of rhizobia on the nodulation and establishment of Trifolium ambiguum. Proceedings of the 10th Australian nitrogen fixation conference: In Press.

Patrick, H.N.; Lowther, W.L. 1994. Inoculation for successful establishment of Caucasian clover. Proceedings of the NZ Grassland Association 56: this volume.

Scott, D. 1985. Plant introduction trials: genotypeenvironment analysis of plant introductions for the high country. NZ journal of experimental agriculture 13: 117- 127.

Scott, D.; Mason, C.R. 1992. Potential for high country pasture improvement from planting of rhizome fragments of spreading legumes. Proceedings of the NZ Grassland Association 54: 127-129.

Spencer, K.; Hely, F.W.; Govaars, A.G.; Zorin, M.; Hamilton, L.J. 1975. Adaptability of Trifolium ambiguum Bieb. to a Victorian montane environment. Journal of Australian Institute of Agricultural Science 41: 268-270.

Strachan, D.E.; Nordmeyer, A.H.; White J.G.H. 1994. Nutrient storage in roots of hexaploid Caucasian clover._Proceedings_of-the-NZ-Grassland Association 56: this volume.

Woodman, R.F.; Keoghan, J.M.; Allan, B.E. 1992. Pasture species for drought-prone lower slopes in the South Island high country. Proceedings of the NZ Grassland Association 54:115- 120.

Woodman, R.F. 1993. Effects of direct drilling on the establishment on the establishment and growth of birdsfoot trefoil in montane tussock grasslands. Proceedings of the XVII International Grassland Congress: 1738-1740. 